\title{
Synthesis and Biological Evaluation of Isonicotinic Acid Hydrazide Conjugated with Diethyelenetriaminepentaacetic Acid for Infection Imaging
}

\author{
Puja Panwar Hazari ${ }^{1}$, Krishna Chuttani ${ }^{1}$, Nitin $\operatorname{Kumar}^{1}$, Rashi Mathur ${ }^{1}$, Rajnish Sharma ${ }^{1}$, \\ Baljinder Singh ${ }^{2}$ and Anil K. Mishra ${ }^{*}, 1$ \\ ${ }^{I}$ Division of Cyclotron and Radiopharmaceutical Sciences, Institute of Nuclear Medicine and Allied Sciences, Brig SK \\ Mazumdar Road, Delhi-110054, India \\ ${ }^{2}$ Post Graduate Institute of Medical Education and Research, Sector-12, Chandigarh-160 012, India
}

\begin{abstract}
Introduction: Isonicotinic acid hydrazide (INH) was coupled to diethylenetriaminepentaacetic acid (DTPA) via amide linkage. Primary object of the present invention was to propose a novel INH derivative based on DTPA, which form stable complexes with most of lanthanides and transition metals in periodic table. Another object of the present invention was to introduce a chelating group in INH without compromising its biological activity for early diagnosis of infection using nuclear medicine and MR techniques.
\end{abstract}

Methods: The DTPA-bis(INH) was synthesized in high yield using simple synthetic procedure. Radiochemical purity was ascertained chromatographically using different solvent system. Blood kinetics in rabbits and biodistribution in mice were studied. The ability of DTPA-bis(INH) to target infection site in vivo was assessed by gamma scintigraphic studies of normal rabbit and rabbit with induced tuberculosis. Preliminary clinical studies were done in patients with known tuberculoses lesions.

Results: DTPA-bis(INH) was characterized using spectroscopic techniques. The complex was successfully labeled with ${ }^{99 \mathrm{~m}} \mathrm{Tc}$ radionuclide with more than $95 \%$ labeling efficiency. It was found stable up to $24 \mathrm{~h}$. Blood kinetics showed rapid first pass clearance with biological half life $t_{1 / 2}(F)$ of $11 \mathrm{~min}$. Biodistribution in tuberculose induced Balb/c mice showed target to muscle ratio $4.53 \pm 0.89$ after 4 h post injection. Gamma scintigraphy of normal as well as rabbits with induced tuberculosis was carried out. An appreciable activity was visualized in liver and kidneys. In infection induced rabbit similar pattern was observed with the accumulation of activity at the tuberculose site at $4 \mathrm{~h}$ post injection. Clinical scintigraphy with ${ }^{99 \mathrm{~m}} \mathrm{Tc}-\mathrm{DTPA}$-bis(INH) clearly indicated the accumulation of the tracer at the tuberculose region in six patients (median age 46 years, range 28-69 years, females; $n=2$ and males; $n=4$ ) which were found positive for Mycobacterium tuberculosis in bacterial culture analysis.

Conclusions: From the present work it can be concluded that the radiolabeled DTPA-bis(INH) accumulates at the site of infection.

Keywords: $\mathrm{INH}$, isoniazid, chelating agent, ${ }^{99 \mathrm{~m}} \mathrm{Tc}$, infection imaging.

\section{INTRODUCTION}

The spread of multidrug resistance in the most pathogenic causative agents, Mycobacterium tuberculosis and Plasmodium falciparum underscores the need to identify active compounds with early diagnostic properties. Despite the worldwide ravages of tuberculosis and malaria chemotherapeutic regimens against these two diseases have remained largely unchanged. Isoniazid (isonicotinic acid hydrazide (INH) has been utilized as frontline agent in drug composition to treat Mycobacterium tuberculosis [1-3]. INH is highly effective for the treatment of experimentally induced tuberculosis in animals and is definitely superior to streptomycin. Unlike streptomycin INH penetrates cells with

*Address correspondence to this author at the Division of Cyclotron and Radiopharmaceutical Sciences, Institute of Nuclear Medicine and Allied Sciences, Brig SK Mazumadar Road, Timarpur, Delhi-110054, India; Tel: 9111 23984480; Fax: 9111 23919509; E-mail: akmishra@inmas.org ease and is just as effective against bacilli growing with in cells as it is against those growing in culture media. It is generally recognized that $\mathrm{INH}$ is a prodrug which is activated through an oxidation reaction catalyzed by an endogenous enzyme. This enzyme, katG, which exhibits catalase-peroxidase activity, converts INH to a reactive species capable of acetylation of an enzyme system found exclusively in M. tuberculosis. Evidence in support of the activation of INH reveals that INH resistant isolates have decreased catalase activity and is associated with the deletion of the catalase gene, katG [4]. Furthermore reintroduction of the gene into resistant organisms results in restored sensitivity of the organism to the drug. Reaction of INH with catalase-peroxidase results in formation of isonicotinaldehyde, isonicotinic acid and isonicotinamide which can be accounted for through the reactive intermediate isonicotinoyl radical (I) or perisonicotinic acid (II). Evidence has been offered both for and against the reaction catalyzed by catalase-peroxidase activated by INH with a portion of the enzyme inhA, an enzyme involved in the biosynthesis of 
mycolic acids. The mycolic acids are important constituents of the mycobacterium cell wall in that they provide a permeability barrier to hydrophilic solutes. The enzyme inhA produced under the control of the gene inhA, is a NADH dependent enoyl reductase protein, which is thought to be involved in double bond reduction during fatty acid elongation. INH specifically inhibits long chain fatty acid synthesis [5-7].

$\mathrm{INH}$ has been chosen as a ligand directly labeled with ${ }^{99 \mathrm{~m}} \mathrm{Tc}$ for diagnosis of tuberculosis [8]. The other strategies of labeling INH with ${ }^{99 \mathrm{~m}} \mathrm{Tc}$ involved the derivatization of isoniazid to its $\mathrm{N}$, $\mathrm{N}$-diacetic acid derivative, which was used as a tridentate ligand for labeling with the $\left.{ }^{99 \mathrm{~m}} \mathrm{Tc}(\mathrm{CO})_{3}\left(\mathrm{H}_{2} \mathrm{O}\right)_{3}\right]^{+}$synthon [9]. But for a successful use of the isotope in antibiotic labeling an antiinfective drug has to be conjugated with multidentate ligand by using the chelate approach. Thus, the prerequisites of ideal imaging agent like fast complex formation and good radiochemical yield have to be fulfilled to avoid non-specific binding and label transfer in vivo to the competing serum protein, and to preserve the affinity of the INH conjugate. INH derivatives have been synthesized and tested for antituberculotic activity and the chemical modification of hydrazine functional group of INH maintains its strong antimycobacterial action as reported in literature [10-16].

Polyaminopolycarboxylic acids based chelating agents have given successful performances in labeling antibodies with some metallic radionuclides, especially ${ }^{111} \mathrm{In}$, and various other lanthanides. The anhydride derivatives of DTPA are generally easier to synthesize because of the commercial availability of DTPA.

A general synthetic approach for the development of a new infection imaging agent has been elaborated. The overall yield of synthesis starting from DTPA anhydride was found to be above $80 \%$. In particular, complexation of DTPA moiety with ${ }^{99 \mathrm{~m}} \mathrm{Tc}$ showed excellent results as metallopharmaceutical for medical imaging. The main objective of our study was to design and synthesize a novel INH derivative based on DTPA, which form stable complexes with most of lanthanides and transition metals in periodic table. Secondly, to introduce a chelating group without compromising the biological activity of antiinfective drug for the diagnosis of infection using nuclear medicine and MR techniques.

We report here on the achievement of the first aspects with a new DTPA conjugated INH. The work reported in the literature has shown that DTPA conjugated [DTPA-B-(SLex)A] forms stable complexes with lanthanides and transition metals [17]. Moreover, the complex with the INH-DTPA reflected increased kinetic ability of ${ }^{99 \mathrm{~m}} \mathrm{Tc}$ - complex as compared to the unmodified INH. We have therefore continued our studies towards the conjugation or introduction of chelating moieties to label antiinfective drugs, which are an additional benefit to avoid nonspecific binding of ${ }^{99 \mathrm{~m}} \mathrm{Tc}$ to use as infection imaging agents.

\section{EXPERIMENTAL PROCEDURES}

\subsection{Preparation of the Tracer}

\subsubsection{Materials}

Isoniazid, DTPA, Dimethylformamide (anhydride) and triethylamine were purchased from Aldrich-Sigma Co. Technetium-99m was procured from Regional Center for radiopharmaceutical (Northern region), Board of Radiation and Isotope Technology (BRIT), Department of Atomic Energy.

HPLC analysis was performed employing Beckman C-18 reversed phase column $(250 \mathrm{~mm} \times 4.6 \mathrm{~mm})$. A mobile phase $0.05 \% \mathrm{TFA} /$ methanol $(7: 1 ; \mathrm{v} / \mathrm{v})$ and a flow rate of 0.5 $\mathrm{mL} / \mathrm{min}$ were used. Mass spectroscopic analysis was obtained using Agilent 1100 coupled with LC operation in ESI (electro spray ionization) positive/negative mode. Gamma ray spectrometer type GRS23C, serial no 458-425 of Electronic Cooperation of India Pvt. Ltd. (ECIL) was used for determining the amount of activity ( $\gamma$ emitter) in the samples. Gamma scintillation camera Hawkeye was used for imaging of animals. Patient imaging was done on HAWKEYE (INMAS) and ECAM, Siemens (PGIMER, Chandigarh).

\subsubsection{Synthesis of DTPA-bis(INH) Conjugate}

DTPA anhydride $(0.1 \mathrm{~g} ; 0.28 \mathrm{mmol})$ and INH $(0.0844 \mathrm{~g}$; $0.62 \mathrm{mmol}$ ) were dissolved in $5 \mathrm{ml}$ of DMF (anhyd.) and 15 molar equivalents of triethylamine $(257.6 \mu \mathrm{L})$ was then added. The reaction was allowed to proceed for $24 \mathrm{~h}$. Completion of the reaction was checked by running TLC plates in $0.05 \%$ TFA/methanol $(3: 2 ; \mathrm{v} / \mathrm{v})$ [ Rf for INH: 0.89 ; Rf for DTPA- bis(INH): 0.75]. Triethylamine and DMF were evaporated under reduced pressure at $50{ }^{\circ} \mathrm{C}$. The product was lyophilized and stored at $-20^{\circ} \mathrm{C}$ until use. The chemical purity of DTPA-bis(INH) conjugate was examined by analytical HPLC on Beckman C-18 reverse phase column $(250 \mathrm{~mm} \times 4.6 \mathrm{~mm})$. Mass spectrum was obtained using Agilent 1100 coupled with LC in ESI positive/negative mode.

Yield: $82 \% 1 \mathrm{H}$ NMR $\left(400 \mathrm{MHz}, \mathrm{D}_{2} \mathrm{O}\right) \delta 8.74$ (pyr, d, $J=$ $12 \mathrm{~Hz}), 7.7(\mathrm{~d}, J=12 \mathrm{~Hz}) 4.26(\mathrm{~s}), 3.56\left(\mathrm{~s},-\mathrm{CO}-\mathrm{CH}_{2}-\mathrm{N}\right), 3.32-$ $2.46\left(\mathrm{~m},-\mathrm{CH}_{2}-\mathrm{CH}_{2}-\right)$ Calc. Mass of DTPA-bis(INH) is 631.24, found $[\mathrm{m} / \mathrm{z}]\left[\mathrm{M}+\mathrm{H}^{+}\right]$at 632.3 . Elemental anal. calc. for $\mathrm{C}_{26} \mathrm{H}_{33} \mathrm{~N}_{9} \mathrm{O}_{10}$ : $\mathrm{C}$ (49.44\%); $\mathrm{H}(5.27 \%) ; \mathrm{N}$ (19.96\%); O (25.33\%), found C (49.43\%); H (5.29\%); N (19.94\%); O (25.34\%).

\subsubsection{Biological Activity of DTPA- bis (INH)}

Bacterial Isolate. M. tuberculosis $\mathrm{H} 37 \mathrm{Rv}$ culture was stored at $-80^{\circ} \mathrm{C}$ in Middlebrook $7 \mathrm{H} 9$ broth. For each study, aliquots were thawed and incubated under $5 \% \mathrm{CO}_{2}$ at $37^{\circ} \mathrm{C}$ in Middlebrook 7H9 broth for 4 days. The standard bacterial suspension of $4 \mathrm{mg} / \mathrm{mL}$ prepared as per the reported method [18] was used as inoculum with the help of a loop (3 $\mathrm{mm}$ internal diameter) and inoculated on to LJ slants. The culture bottles were incubated at $37{ }^{\circ} \mathrm{C}$ and readings were taken after 4 weeks of incubation. The MIC (minimal inhibitory concentration) was determined by counting the colony forming units (CFU) and comparing with control cultures. To assess the quality of inoculum, culture control was read as growth of ++ (more than 100 colonies, usually 150-200 colonies) and considered essential for reading the results. An isolate was considered resistant if it yielded a growth of 20 colonies or more at a given concentration of drug and sensitive when there was no growth. 


\subsubsection{Radiolabeling of DTPA-bis(INH) with ${ }^{99 m} \mathrm{Tc}$}

Covalent attachment of a strong chelating agent to INH provides binding sites to which reduced ${ }^{99 \mathrm{~m}} \mathrm{Tc}$ may be strongly bound. ${ }^{99 \mathrm{~m}}$ Tc-labeled DTPA-bis(INH) conjugate was prepared by using a simple reduction method using $\mathrm{SnCl}_{2} \cdot 2 \mathrm{H}_{2} \mathrm{O}$ as the reducing agent.

Radiolabeled DTPA-bis(INH) conjugate was prepared by dissolving $2.0 \mathrm{mg}$ of the reaction product in $1 \mathrm{~mL}$ of distilled water. To this solution $150 \mu \mathrm{g}$ of stannous chloride (1 $\mathrm{mg} / \mathrm{mL}$ solution made in $1 \mathrm{~N} \mathrm{HCL}$ ) was added and the $\mathrm{pH}$ of the solution was finally adjusted to 7.5 using $0.5 \mathrm{M}$ $\mathrm{NaHCO}_{3}$. Solution was then passed through $0.22 \mu \mathrm{m}$ Millipore filter. $74 \mathrm{MBq}$ of activity was added drop wise and the reaction mixture was incubated at room temperature for $15 \mathrm{~min}$

\subsubsection{Quality Control of ${ }^{99 m}$ Tc-DTPA-bis(INH) Conjugate}

Radiochemical purity and labeling efficiency of the product was ascertained by ascending instant thin layer chromatography. ITLC strips were utilized as stationary phase and acetone as the mobile phase. The procedure involved spotting $2 \mu \mathrm{L}$ sample of DTPA-bis(INH) radiopharmaceutical onto chromatography strip $10 \mathrm{~cm}$ in length. After developing in the solvent, the strips were cut into two portions (top: bottom: 1:3), and activity in each portion was measured in the form of counts using a gamma scintillation counter. Percentage activity at the origin and the solvent front was determined. ${ }^{99 \mathrm{~m}}$ Tc-DTPA-bis(INH) conjugate remained at the origin and free technetium travelled with the solvent front $\left(\mathrm{R}_{\mathrm{F}}=0.9-1.0\right)$. Percentage of colloid was determined using pyridine: acetic acid: water $(3: 2.5: 1)$ as the mobile phase. The radiochemical purity was found to be greater than $95 \%$.

\subsubsection{In Vitro Stability Studies}

In vitro stability studies were carried out by incubating the reaction mixture under physiological condition $\left(37{ }^{\circ} \mathrm{C}\right.$, $\mathrm{pH}$ 7.4) for various time intervals. Percentage radiolabeling was calculated for $0,1,2,3,4$ and 24 hours.

\subsection{Animal Studies}

All animal experiments were performed in accordance with the guidelines of INMAS animal ethics committee. Female mice weighing 22-30g of Balb/c strain were used for biodistribution studies. Rabbits of New Zealand strain weighing 3 to $3.5 \mathrm{~kg}$ were used for blood kinetics, serum protein binding study and imaging. The animals were selected at random from the stock colony maintained in the animal in house facility. The animals were reared on laboratory chow pallets, fed ad libitum and had free access to food and water at all the time. The room was maintained at $25 \pm 2{ }^{\circ} \mathrm{C}$ with natural daytime light and no light after $19 \mathrm{~h}$ until morning.

\subsubsection{In Vivo Stability Study}

This study was done to evaluate the stability of ${ }^{99 \mathrm{~m}} \mathrm{Tc}$ labeled DTPA-bis(INH), after administering the radiopharmaceutical into the blood stream of the test animal. In vivo stability study was carried out by injecting $18.5 \mathrm{MBq}$ of radiolabeled compound through the dorsal ear vein of the rabbit. Blood was withdrawn from the other ear vein at different time intervals $(5,10,15,30,60,120,240,360,480$, 1440 minutes). Every time the blood was withdrawn, ITLC was run in acetone and percentage radiolabeling and free

${ }^{99 \mathrm{~m}}$ Tc was determined. Blood kinetics studies were done in normal rabbits. $18.5 \mathrm{MBq}$ of radiolabeled compound was injected intravenously through the dorsal ear vein. Blood was withdrawn from the other ear vein at different time intervals from $5 \mathrm{~min}$ to 24 hours. Persistence of activity in the circulation was calculated assuming total blood volume as $7 \%$ of the body weight.

\subsubsection{Experimental Models}

M. tuberculosis $\mathrm{H} 37 \mathrm{Rv}$ culture was stored at $-80{ }^{\circ} \mathrm{C}$ in Middlebrook $7 \mathrm{H} 9$ broth. For each study, aliquots were thawed and incubated under $5 \% \mathrm{CO}_{2}$ at $37^{\circ} \mathrm{C}$ in Middlebrook $7 \mathrm{H} 9$ broth for 4 days. Bacteria were counted using a haemocytometer and diluted in LB medium for use.

In four groups of $20 \mathrm{Balb} / \mathrm{c}$ mice infection was induced in the thigh muscle by intramuscular injection of $1.5 \times 10^{8}$ viable bacilli of $M$. tuberculosis $\mathrm{H} 37 \mathrm{Rv}$ in a volume of 0.1 $\mathrm{mL}$ of LB medium. To prepare the infection model in rabbits, aliquots of the bacterial cultures were diluted in LB medium to a concentration of $1 \times 10^{12}$ cells $/ \mathrm{mL}$, and $0.1 \mathrm{~mL}$ was administered subcutaneously in one thigh of each of the rabbit $(n=3)$.

\subsubsection{Biodistribution in Mice}

When the swelling of the inoculated muscle was apparent the mice were used for the biodistribution study. 3.7 MBq of radiolabeled compound was injected in the tail vein of each mouse. Mice were dissected at 1, 2, 4 and $24 \mathrm{~h}$. Different organs were taken out, weighed and counted in the gamma counter. Uptake of radiopharmaceutical in each sample was calculated and expressed as percentage injected dose per organ.

\subsubsection{Scintigraphy in Rabbits}

18.5 $\mathrm{MBq}$ of radiolabeled compound was injected intravenously through the dorsal ear vein of the rabbit. Images were taken under planar gamma camera equipped with pinhole collimator. Images were obtained at $1 \mathrm{~h}, 2 \mathrm{~h}, 4$ $\mathrm{h}$ and $24 \mathrm{~h}$ post injections. ROI was calculated in both infected and normal thigh regions.

\subsection{Clinical Studies}

Human protocols have been approved by Institutional human ethics committee

\subsubsection{Scintigraphy}

Whole body images were obtained using dual head gamma camera. ${ }^{99 \mathrm{~m}}$ Tc-DTPA-bis(INH) imaging was performed after i.v. administration of $15 \mathrm{mCi}(555 \mathrm{MBq})$ radiotracer in six patients (median age 46 years, range 28-69 years, females: $n=2$ and males: $n=4)$. Whole body scan was done after $1 \mathrm{~h}, 3 \mathrm{~h}, 6 \mathrm{~h}$ and $24 \mathrm{~h}$ injection of radiotracer as a standard protocol and 2 patients were also imaged at 5, 10, 30, 45, 60, 180 minutes. Semiquantitative analysis was generated from Region of Interest (ROI) placed over areas counting average counts per pixel with maximum radiotracer uptake on the infection site and compared to symmetric counterparts with ROI in soft tissues. MDP scans were also conducted on patients. 


\subsection{Data Analysis}

All data are reported as mean values \pm Standard Deviation (S.D.). Data comparison was performed by using Student's t-test. $p<0.05$ was considered as significantly different.

\section{RESULTS}

\subsection{Synthesis of DTPA-bis(INH)}

The synthesis of DTPA-bis(INH) is shown in Fig. (1). Synthesis of DTPA anhydride was performed as reported in the literature [7]. The polyaminopolycarboxylate ligand having two reactive sites (bisanhydride of DTPA) for the conjugation of antibiotic favors the formation of complex with only one ligand per metal atom which is required for in vivo stability and biological activity. Two molecules of INH were conjugated to bisanhydride of DTPA. The final product was obtained in $82 \%$ yield. Reaction was monitored on HPLC [INH, $t_{R}=5.76$ min, DTPA-bis(INH) $t_{R}=6.13$ min.(See supporting information). Solvent system used for HPLC analysis was $0.05 \%$ TFA/methanol $(7: 3 \mathrm{v} / \mathrm{v})$ with a flow rate of $0.5 \mathrm{~mL} / \mathrm{min}$ over $20 \mathrm{~min}$. Using the same column, DTPA-bis(INH) ( $\left.\mathrm{t}_{\mathrm{R}}=6.13 \mathrm{~min}\right)$ was separated from INH $\left(t_{R}=5.76 \mathrm{~min}\right)$ and mass spectroscopic analysis was done and molecular peak $\left[\mathrm{M}+\mathrm{H}^{+}\right]$was obtained in ESI positive (Fig. 2).

\subsection{MIC of DTPA-bis(INH) Conjugate}

The MIC for isoniazid and DTPA-bis(INH) in $M$. tuberculosis isolate was found to be $0.02 \mu \mathrm{g} / \mathrm{mL}$ and 0.025 $\mu \mathrm{g} / \mathrm{mL}$ respectively. This clearly indicates that INH and DTPA-bis(INH) conjugate kill the tubercle bacilli corresponding to the MIC to M. tuberculosis of $0.02-0.025$ $\mu \mathrm{g} / \mathrm{mL}$.

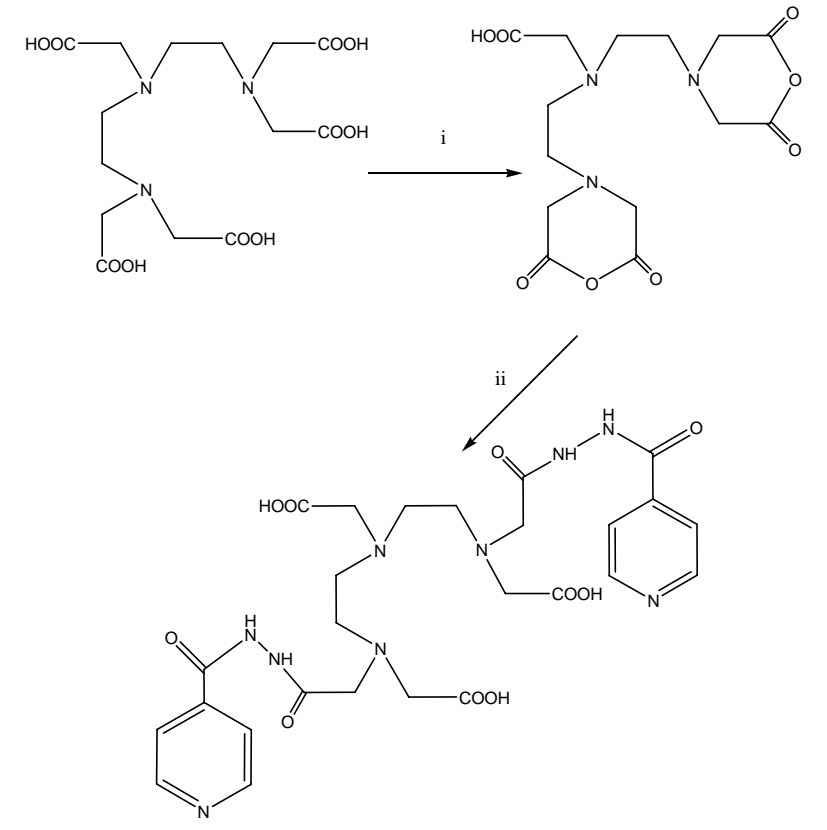

Fig. (1). Synthesis of bis(amide) of Diethyelene triaminepentaacetic Acid: DTPA-bis(INH) Reagents : i) Dimethylformamide, pyridine, acetic anhydride ii) triethylamine.

\subsection{Radiolabeling of DTPA-bis(INH) Conjugate with ${ }^{99 \mathrm{~m}}$ Technetium}

The DTPA-bis(INH) conjugate was successfully labeled with ${ }^{99 \mathrm{~m}} \mathrm{Tc}$ with more then $95 \%$ labeling efficiency. It was sufficiently stable up to $24 \mathrm{~h}$. Variation in the amount of $\mathrm{SnCl}_{2} \cdot 2 \mathrm{H}_{2} \mathrm{O}$ and $\mathrm{pH}$ had a significant influence on the

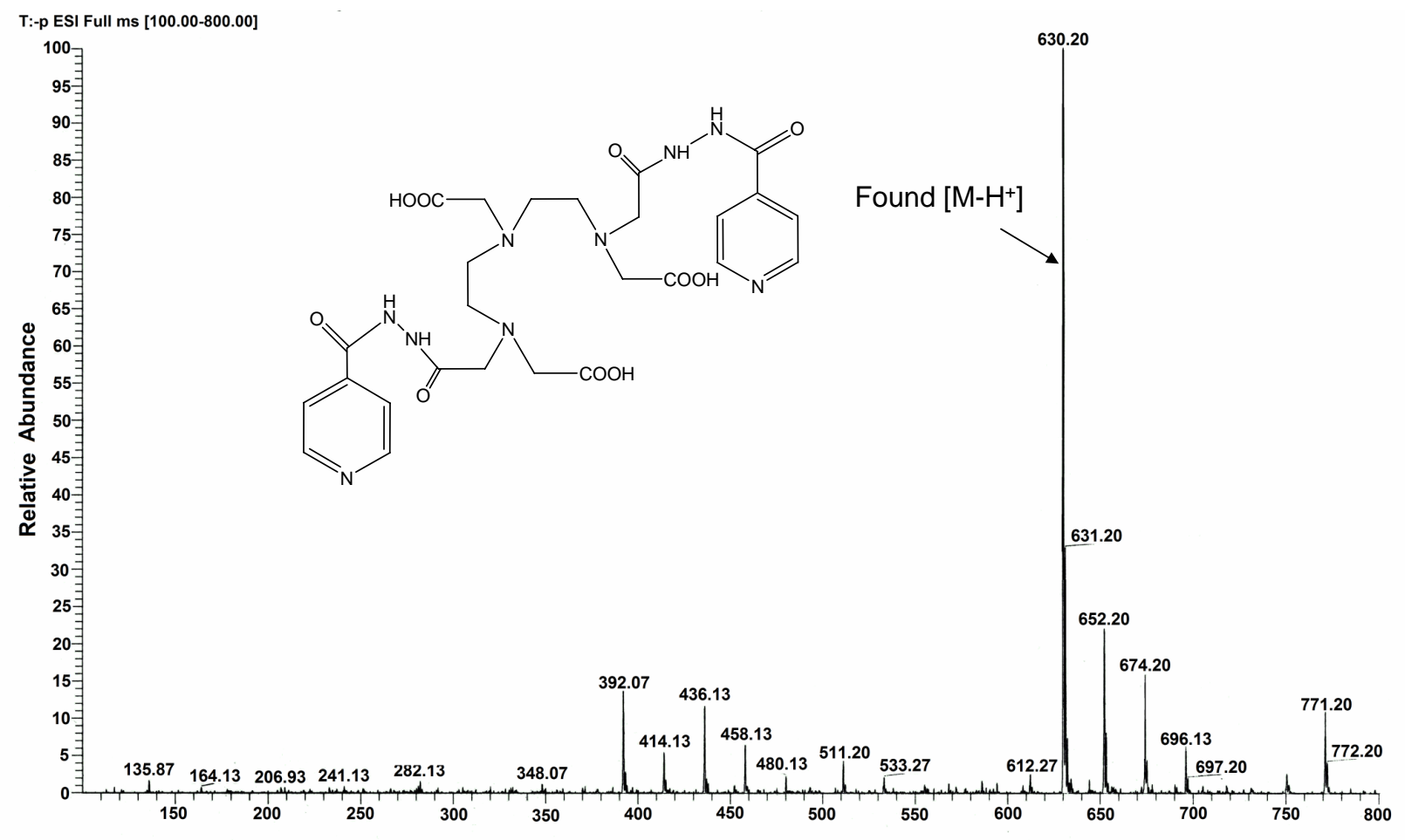

Fig. (2). Mass Spectrum of DTPA-bis(INH) in ESI positive mode. 
labeling yield. Keeping the other factors constant, the concentration of the $\mathrm{SnCl}_{2}$ was varied between 50-300 $\mu \mathrm{g}$ and the optimal yield was obtained at $150 \mu \mathrm{g}$. The percentage of colloids formed was $2.88 \%$, increasing the concentration of stannous chloride increases the percentage of colloid. Variation in $\mathrm{pH}$ also affected the labeling efficiency. The optimum $\mathrm{pH}$ was found to be 7.5. At $\mathrm{pH} 7.5$ all the carboxyl groups of DTPA deprotonated as good binder for ${ }^{99 \mathrm{~m}} \mathrm{Tc}$. Thus the complex between DTPA-bis(INH) and ${ }^{99 \mathrm{~m}} \mathrm{Tc}$ at $\mathrm{pH} 7.5$ is more stable than that in acidic condition.

The conjugated INH was labeled with a specific activity 740-112 MBq/mg of antibiotic. Labeling efficiency was measured by ascending paper chromatography on ITLC-SG strips. Results of radiolabeling of the conjugate were found to be $98.5 \pm 0.30 \%$. ITLC-SG results in acetone showed that $1.5-2 \%$ or less free pertechnetate ran with the solvent front $(\mathrm{Rf}=0.7-1.0)$. In $10 \%$ Ammonium acetate and methanol (1:1) solvent system, all the activity was found to be on the base of ITLC-SG strips which indicated the formation of radiolabeled conjugate.

\subsection{Cysteine Challenge Tests}

Radiolabeled conjugates was challenged with (25-100 $\mathrm{mM}$ ) of cysteine to test the stability of the radiolabeled DTPA-bis(INH). Major transcomplexation of ${ }^{99 m}$ Tc to 25 $\mathrm{mM}$ cysteine was observed for unmodified INH that was found to be $45 \%$. DTPA-INH showed $5.9 \%$ transcomplexation of ${ }^{99 \mathrm{~m}} \mathrm{Tc}$ to $25 \mathrm{mM}$ cysteine. Approximately more than $92 \%$ of the radioactivity remains associated with the conjugate after $2 \mathrm{~h}$ challenge at $37{ }^{\circ} \mathrm{C}$ with cysteine (Fig. 3).
The ${ }^{99 m}$ Tc-DTPA-bis(INH) complex was highly hydrophilic. Hydrophilicity of the complex was found to be $99.20 \%$ as determined by dichloromethane-water system. Such a high hydrophilicity accounts for very fast kinetics shown by the radiopharmaceutical. Since it is highly hydrophilic it can not be used as a diagnostic agent for imaging CNS tuberculosis. However it can be used efficiently for diagnosing other types of extrapulmonary and pulmonary tuberculosis.

\subsection{Blood Clearance of ${ }^{99 m}$ Tc-DTPA-bis(INH)}

Blood kinetics data of radiolabeled drug was obtained at various time intervals. Blood kinetics study show a very rapid first pass blood clearance approximately $60 \%$ clearance by $5 \mathrm{~min}$. and $>85 \%$ clearance by $1 \mathrm{~h}$. Blood clearance $T_{1 / 2}=11$ min shows a very fast first order kinetics (Fig. 4). Such a fast kinetics is mainly because of highly hydrophilic nature of the drug.

\subsection{Biodistribution Studies of ${ }^{99} \mathrm{~m}$ Tc-DTPA-bis(INH) in Mice}

Biodistribution data of radiolabeled drug was obtained at various time points In terms of percentage-injected dose/organ is shown in Table 1. Biodistribution study clearly indicated that the major route of excretion of radiopharmaceutical is renal, since very high activity of the labeled conjugate was present in kidneys. However at $1 \mathrm{~h}$ post injection the activity was much higher in kidney than that in intestine. Large percentage (almost 80\%) of the excretion of the drug took place in first hour post injection as determined from the blood kinetics study. Correlating both these observation it can be concluded that most of the radiopharmaceutical (about $80 \%$ ) is excreted mainly through

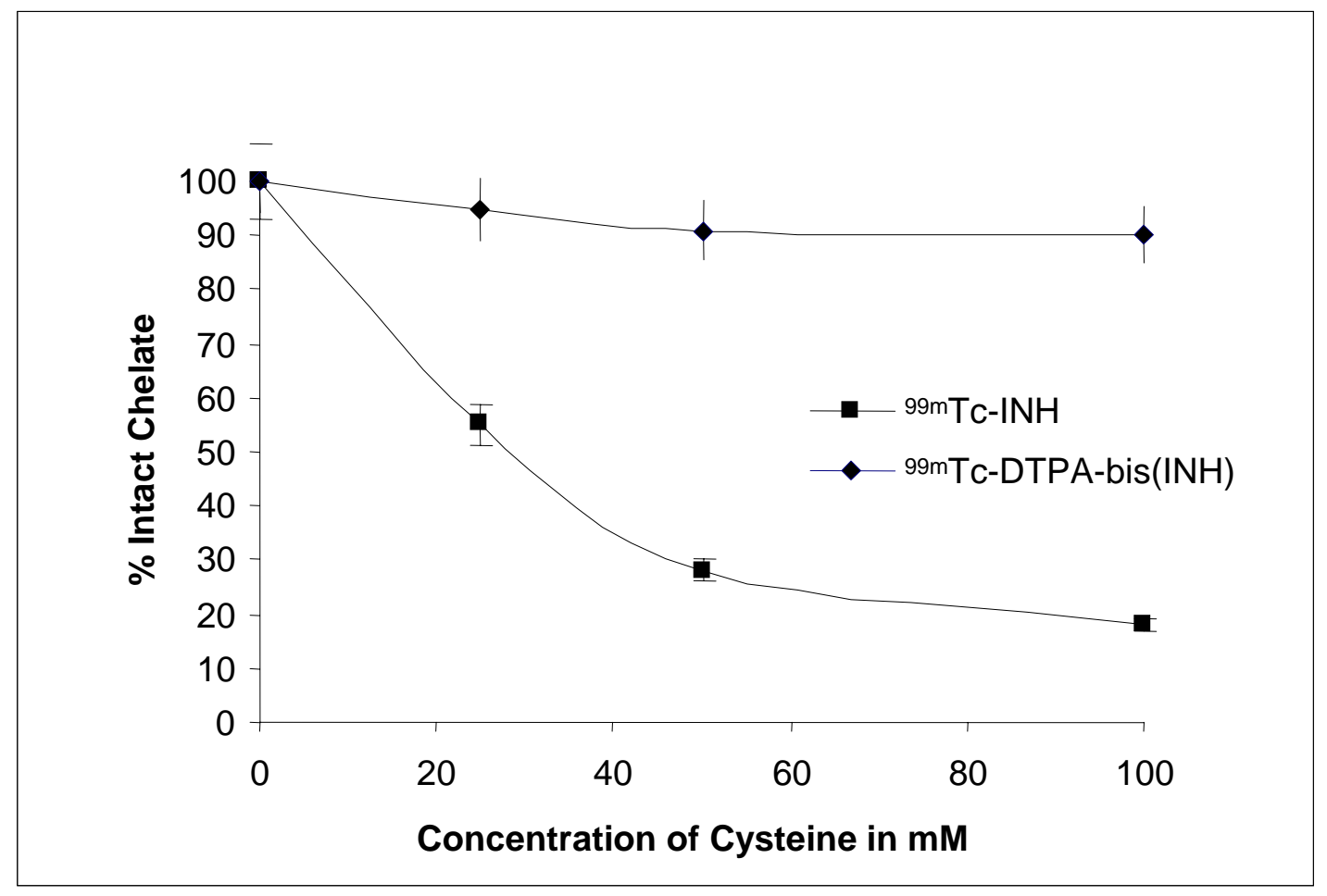

Fig. (3). Cysteine challenge tests to assess in vitro stability of ${ }^{99 \mathrm{~m}} \mathrm{Tc}-\mathrm{INH}$ and ${ }^{99 \mathrm{~m}} \mathrm{Tc}-\mathrm{DTPA}-\mathrm{bis}(\mathrm{INH})$ under physiological conditions. 


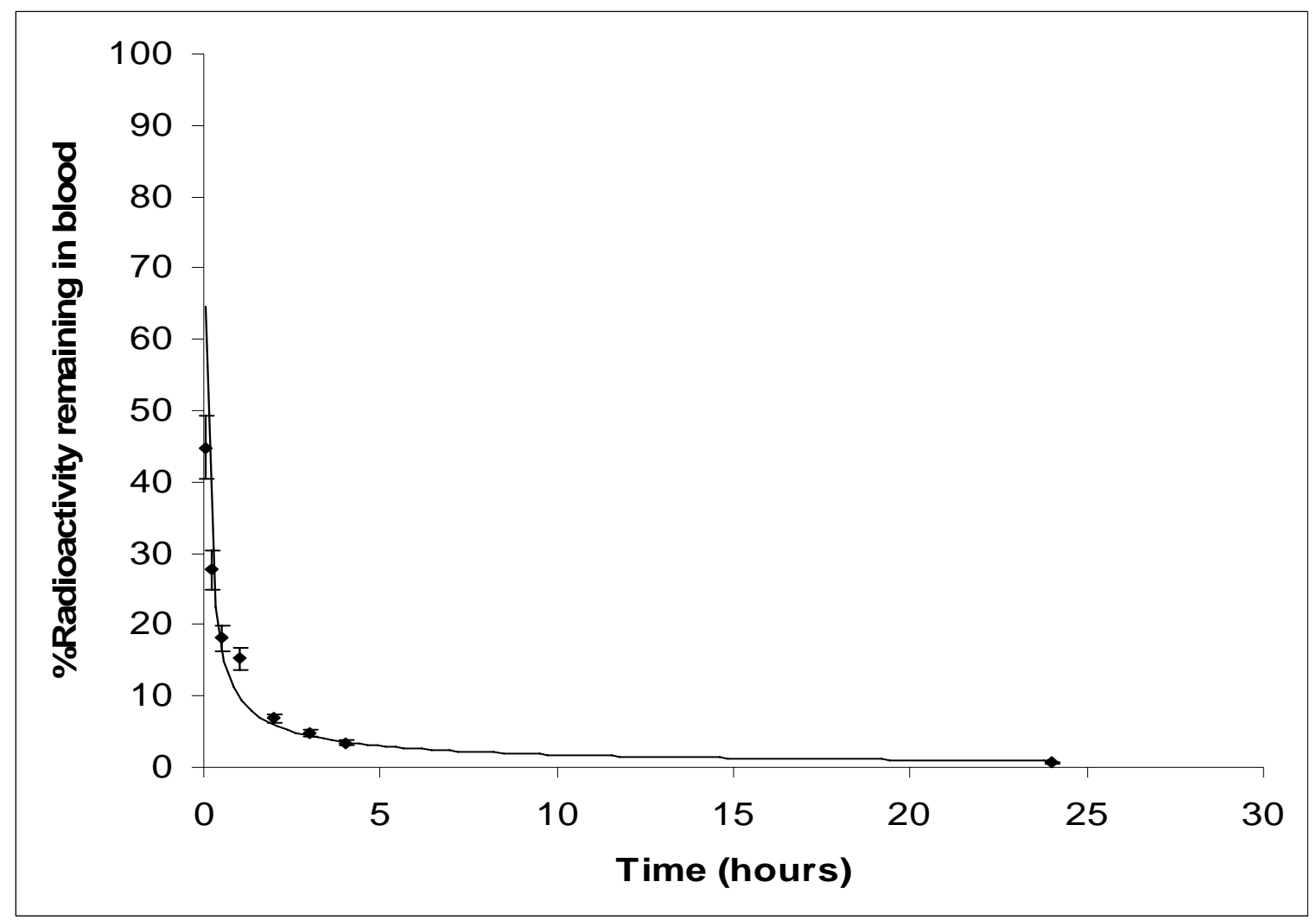

Fig. (4). Blood clearance of ${ }^{99 \mathrm{~m}}$ Tc- DTPA-bis(INH) (18.5 MBq activity) administered through ear vein in normal rabbit.

renal route. However at $4 \mathrm{~h}$ post injection activity is more in intestine than that in urine suggesting that the excretion of rest of the radiopharmaceutical takes place through faeces.

Biodistribution revealed high uptake at the tuberculose site, target to muscle ratio reached $4.53 \pm 0.89$ after $4 \mathrm{~h}$ post injection. Statistical evaluation (t-test) of the data sets of the tuberculose site compared with the contralateral thigh muscle at 1, 2, 4 and $24 \mathrm{~h}$ demonstrated $p$ values $<0.05$ (0.0019).

\subsection{Scintigraphy of ${ }^{99 \mathrm{~m}}$ Tc-DTPA-bis(INH) in Normal and Experimental Rabbit}

Imaging of a normal rabbit and a rabbit with induced tuberculosis was carried out using a gamma camera. In the images obtained in normal rabbits at $1 \mathrm{~h}, 4 \mathrm{~h}$ and $24 \mathrm{~h}$ post injection an appreciable activity was noticed in the liver, kidneys and urinary bladder. In experimental rabbits a similar pattern was observed at $1 \mathrm{~h}$ and $24 \mathrm{~h}$ post injection.

Table 1. Biodistribution of ${ }^{99 \mathrm{~m}}$ Tc-DTPA-bis(INH) in Mice. Data from 4 Groups of Five Mice Each are Expressed as Mean \% ID/g \pm S.D.

\begin{tabular}{|l|c|c|c|c|}
\hline \multicolumn{1}{|c|}{ Organs } & $\mathbf{1 ~ h}$ & $\mathbf{2 ~ h}$ & $\mathbf{4 h}$ & $\mathbf{2 4} \mathbf{~ h}$ \\
\hline \hline Blood & $8.00 \pm 0.070$ & $6.09 \pm 0.710$ & $3.20 \pm 0.170$ & $0.700 \pm 0.110$ \\
\hline Heart & $0.24 \pm 0.014$ & $0.17 \pm 0.020$ & $0.14 \pm 0.010$ & $0.007 \pm 0.001$ \\
\hline Lungs & $0.91 \pm 0.060$ & $0.66 \pm 0.080$ & $0.63 \pm 0.110$ & $0.040 \pm 0.010$ \\
\hline Liver & $6.30 \pm 0.580$ & $6.25 \pm 0.110$ & $5.20 \pm 0.330$ & $0.500 \pm 0.040$ \\
\hline Spleen & $0.34 \pm 0.100$ & $0.20 \pm 0.005$ & $0.17 \pm 0.020$ & $0.035 \pm 0.010$ \\
\hline Kidney & $7.65 \pm 0.520$ & $6.70 \pm 0.280$ & $5.96 \pm 0.700$ & $0.350 \pm 0.050$ \\
\hline Stomach & $0.88 \pm 0.060$ & $0.76 \pm 0.050$ & $0.78 \pm 0.070$ & $0.180 \pm 0.030$ \\
\hline Intestine & $4.63 \pm 0.620$ & $8.56 \pm 0.760$ & $12.82 \pm 1.23$ & $1.340 \pm 0.160$ \\
\hline Bone & $1.32 \pm 0.180$ & $1.52 \pm 0.210$ & $1.25 \pm 0.420$ & $0.220 \pm 0.030$ \\
\hline Brain & $0.31 \pm 0.030$ & $0.28 \pm 0.060$ & $0.36 \pm 0.050$ & $0.120 \pm 0.002$ \\
\hline Muscle & $0.38 \pm 0.030$ & $0.41 \pm 0.040$ & $0.52 \pm 0.030$ & $0.260 \pm 0.050$ \\
\hline Tuberculose Lesion & $1.59 \pm 0.32$ & $1.77 \pm 0.38$ & $2.36 \pm 0.41$ & $1.16 \pm 0.29$ \\
\hline Target / Non Target Ratio & $4.21 \pm 0.47$ & $4.32 \pm 0.42$ & $4.53 \pm 0.89$ & $4.46 \pm 1.2$ \\
\hline
\end{tabular}


(a)

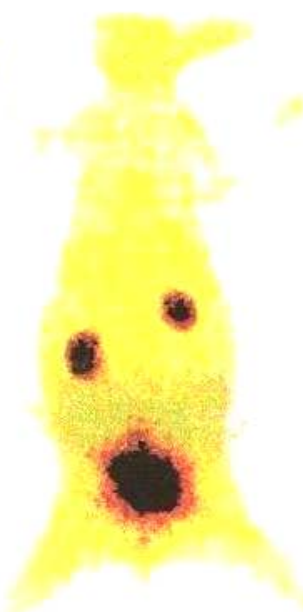

(b)

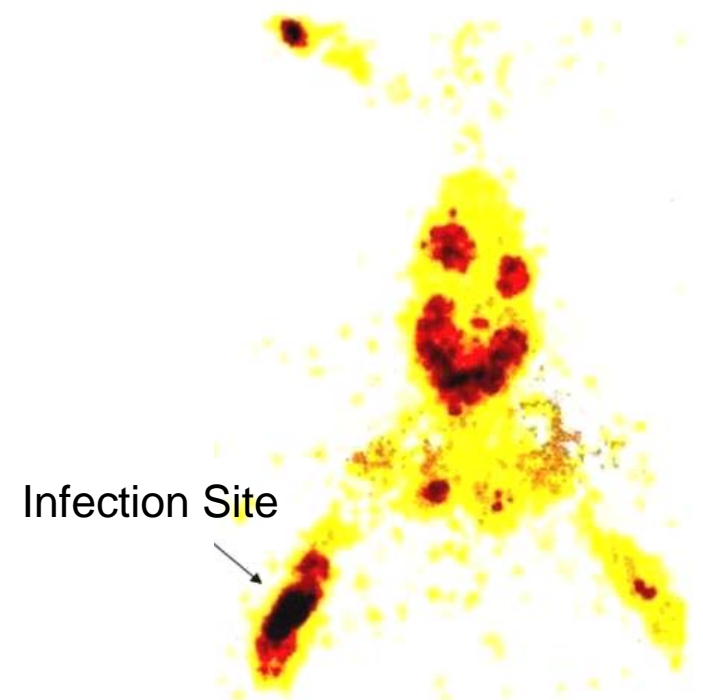

Fig. (5). Whole body gamma scintigraphy of ${ }^{99 \mathrm{~m}}$ Tc-DTPA-bis-INH administered through ear vein in (a) Normal rabbit (b) Rabbit bearing M. tuberculosis infective lesion in left leg at $4 \mathrm{~h}$.

Image taken at $4 \mathrm{~h}$ post injection clearly showed accumulation of radiopharmaceutical at the tuberculose site (Fig. 5). ROIs generated using software (ENTEGRA) exhibited $16.03 \pm 2.89$ target to non target ratio at $4 \mathrm{~h}$ post injection. $p$-values $<0.05$ indicated significant uptake of the radiotracer at tuberculose site.

\subsection{Clinical Studies}

Clinical studies showed a fast renal clearance in all the six patients (median age 46 years, range 28-69 years, females: $n=2$ and males: $n=4$ ). Two hours after administration, a small percentage of the injected activity was removed by the liver in comparison to the kidney. Semiquantitative analysis was generated from Region Of Interest (ROI) placed over areas counting average counts per pixels with maximum radiotracer uptake at the infection site and compared to symmetric counterparts with ROI in soft tissues. Target to non-target ratio at the infection sites are shown in Table $\mathbf{2}$. The mean ratio for the patient studied was found to be $2.84 \pm 0.44 .{ }^{99 \mathrm{~m}}$ Tc-DTPA-bis(INH) scans showing accumulation of the radiotracer concentration in the right hip region and in the right knee joint (anterior and posterior images acquired at $1 \mathrm{~h}, 4 \mathrm{~h}, 24 \mathrm{~h}$ ) are shown in Fig. (6). Blood pool study with ${ }^{99 \mathrm{~m}} \mathrm{Tc}-\mathrm{MDP}$ (known bone imaging agent) was carried out to correlate the accumulation of the radiotracer at the infection site. Insignificant uptake of ${ }^{99 \mathrm{~m}} \mathrm{Tc}-$ MDP at the infection site suggested that the INH conjugate has got specificity towards tuberculose lesion (See supporting information).

\section{DISCUSSION}

The concept of utilizing chelate approach to radiolabel INH was to preserve its biological integrity to bind bacteria for non invasive radiological detection of tuberculose
Table 2. Semiquantative ROI Analysis Showing Infection Site to Soft Tissue (T/NT) in 6 Patients Expressed as Mean \pm S.D.

\begin{tabular}{|c|c|c|}
\hline Patient & $\begin{array}{c}\text { Target/ Non-Target } \\
\text { Ratio (1h) }\end{array}$ & $\begin{array}{c}\text { Target/ Non-Target } \\
\text { Ratio (4h) }\end{array}$ \\
\hline \hline 1 & $2.15 \pm 0.04$ & $2.12 \pm 0.12$ \\
\hline 2 & $2.83 \pm 0.83$ & $2.40 \pm 0.65$ \\
\hline 3 & $3.08 \pm 0.46$ & $2.86 \pm 0.34$ \\
\hline 4 & $2.7 \pm 0.81$ & $1.89 \pm 0.22$ \\
\hline 5 & $3.4 \pm 1.10$ & $2.8 \pm 0.53$ \\
\hline 6 & $3.1 \pm 0.22$ & $2.7 \pm 0.71$ \\
\hline Mean \pm SD & $2.87 \pm 0.44$ & $2.46 \pm 0.39$ \\
\hline Range & $2.7-3.4$ & $1.89-2.86$ \\
\hline
\end{tabular}

infection. This investigation focused on the possibilities and limitations of various unmodified ${ }^{99 \mathrm{~m}}$ Tc-labeled antibiotics including antimicrobial peptides and ciprofloxacin to detect bacterial infections. The sensitivities and specificities reported in the literature for antimicrobial agents for localizing infective foci is that the agent must target the microbe, which is causing the infection. These antimicrobial agents, such as antibiotics, interfere with important metabolic processes or molecules within the microorganism such as DNA synthesis, cell wall/membrane components and protein synthesis, and monoclonal antibodies against microbial specific epitopes. The exploitation of these targets for imaging bacterial infection yield radiopharmaceuticals which specifically accumulate at the site of infection and 


\section{(A)}
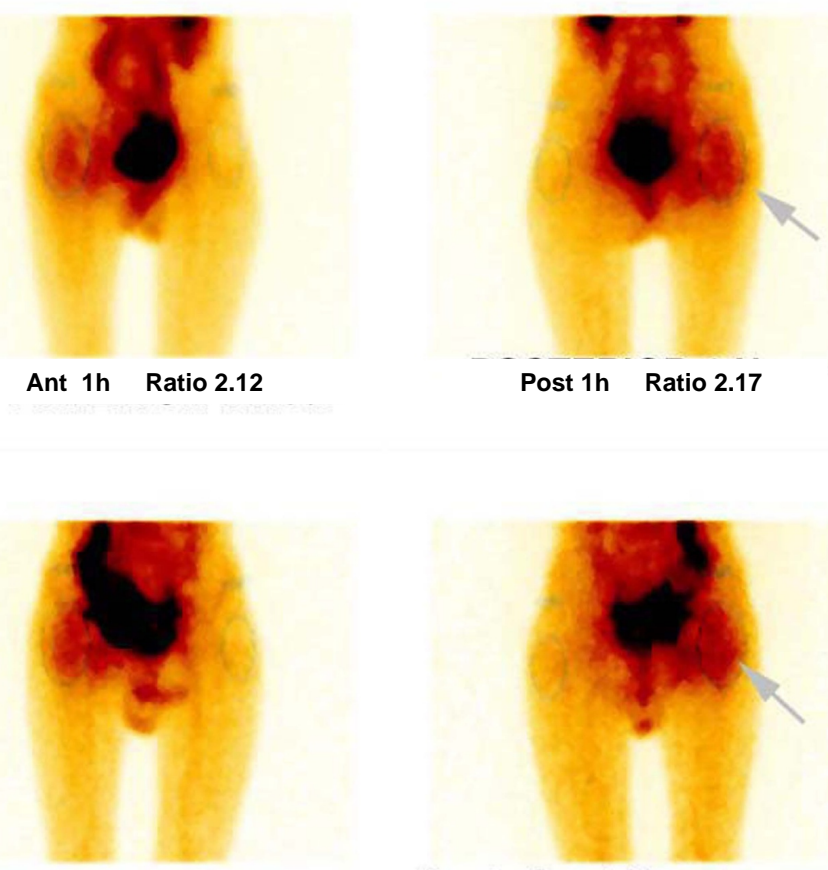

Ant 4h Ratio 2.20

Post 4h Ratio 2.83

(B)

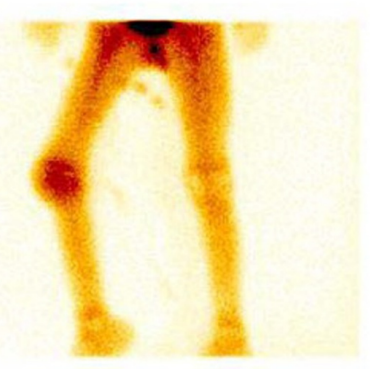

Ant 1h

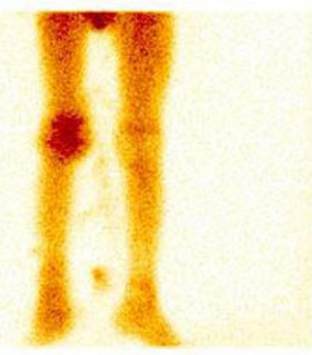

Ant $4 \mathrm{~h}$

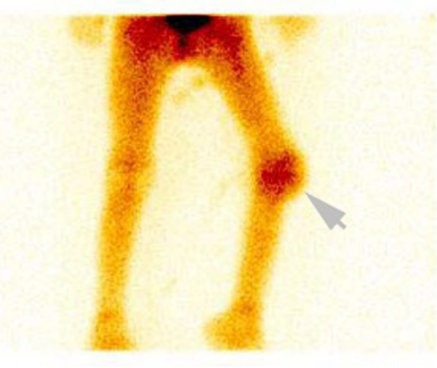

Post 1h

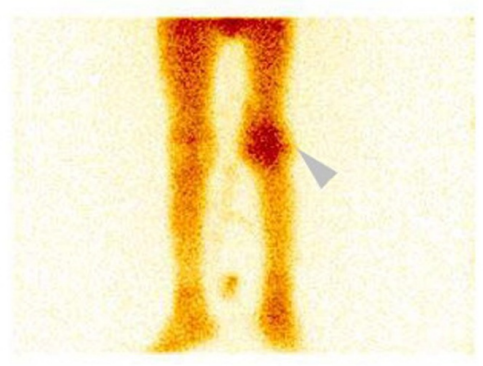

Post 4h

Fig. (6). Whole body gamma imaging using ${ }^{99 \mathrm{~m}}$ Tc-DTPA-bis(INH) in a patient having Mycobacterium tuberculosis infection. (A) Scan showing focus of the radiotracer concentration in the right hip region (anterior and posterior images acquired at $1 \mathrm{~h}$ and $4 \mathrm{~h}$ ). (B) Scan showing focus of the radiotracer concentration in the right knee joint (anterior and posterior images acquired at $1 \mathrm{~h}$ and $4 \mathrm{~h}$ ). 
distinguishes inflammation. The strategic challenge for nuclear medicine for infection imaging is, therefore, to develop radiopharmaceuticals, which bind to the microbe directly and are specific to it. The antibiotic ciprofloxacin and the human neutrophil peptides have been introduced in nuclear medicine as tracers that preferentially detect bacterial infections. ${ }^{99 \mathrm{~m}}$ Tc labeled antimicrobial compounds, such as ciprofloxacin [19, 20] and antimicrobial peptides [21, 22], may be the promising radiopharmaceuticals which distinguish between bacterial infections and sterile inflammatory processes in humans. However, a major drawback with these imaging agents is direct labeling with undefined radiochemistry. Antibiotic such as INH (isonicotinic acid hydrazide) has been utilized as frontline agent in drug mixtures to treat Mycobacterium tuberculosis. In the present study, conjugate of INH has been generated using diethylenetriaminepentaacetic acid anhydride as chelating agent. This chelate has anhydride as reactive group which allows conjugation of INH to the hydrazino group and thereby formation of amide bond that participates along with carboxylates in the radiocomplexation with ${ }^{99 \mathrm{~m}} \mathrm{Tc}$. The two molecules of INH also enhance the hydrogen bonding with INH receptors and do not alter its binding with NADH. The use of this chelating agent to prepare radioconjugate made rapid clearance from blood circulation and normal organs as compared to directly radiolabeled antibiotics as previously described [19-23].

The conjugate was labeled with ${ }^{99 \mathrm{~m}} \mathrm{Tc}$, evaluated in vitro and in vivo for its competence in clinical diagnosis of infection sites. An ideal radiopharmaceutical should have a radiolabeling efficiency of more than $95 \%$. The labeling efficiency of DTPA-bis(INH) was more than this limit and this high labeling efficiency and stability is attributed to the presence of defined multidentate chelating system. Such a high labeling yield and high stability is the prerequisite condition for a good radiopharmaceutical.

The stability of radiolabeled compounds is one of the major problems in formulating radiopharmaceuticals. It must be stable both in vitro and in vivo. Temperature, $\mathrm{pH}$, and light affect the stability of many compounds and the optimal range of these physicochemical conditions must be established for the preparation and storage of labeled compounds. In vivo breakdown of a radiopharmaceutical results in undesirable biodistribution of radioactivity. The complex formed by chelation of ${ }^{99 \mathrm{~m}} \mathrm{Tc}$ with the synthesized DTPA derivative was found to be very strong as suggested by in vitro serum stability and cysteine challenge tests. The biodistribution patterns observed in ${ }^{99 \mathrm{~m}}$ Tc-DTPA-bis(INH) was high uptake in the kidneys with excretion to the urinary bladder, moderate to high uptake in liver. Biodistribution study showed a very fast clearance of radiopharmaceutical from the blood. As far as accumulation of radiopharmaceutical in the RES is concerned, it showed accumulation mainly in liver, very little accumulation in lungs and almost negligible concentration in spleen, heart and brain. However appreciable accumulation is seen in bone, thus, this radiopharmaceutical can also be used effectively in diagnosing tuberculosis associated with bones. The scintigraphic study in rabbit having tuberculose infection demonstrated the appreciable accumulation of ${ }^{99 \mathrm{~m}}$ Tc-DTPA-bis(INH) radiopharmaceutical. In vitro human serum stability studies under physiological conditions suggested that there was least transcomplexation of the labeled drug.

${ }^{99 \mathrm{~m}}$ Tc-DTPA-bis(INH) accumulated in all the six patients having tuberculose infection, thereby making DTPAbis(INH) an ideal SPECT pharmaceutical for evaluating infection caused by Mycobacterium tuberculosis.

\section{CONCLUSION}

The DTPA-bis(INH) has shown substantial potential to be used as an agent for diagnosis of tuberculose sites, especially in patients with extrapulmonary tuberculosis. From the present work it can be concluded that radiolabeled DTPA-bis(INH) accumulates at the site of infection. Moreover, being highly hydrophilic in nature, it was retained at the site of infection even after $24 \mathrm{~h}$. This indicates that some specific mechanism must be involved in the accumulation of radiopharmaceutical at the site of infection, other than enhanced permeability and retention (EPR) effect.

\section{ACKNOWLEDGEMENTS}

We thank Dr. R.P. Tripathi, Director INMAS, for providing necessary facilities. The work was supported by Defence Research and Development Organization, Ministry of Defence, under R\&D project INM -311.

\section{REFERENCES}

[1] Banerjee A, Dubnau E, Quemard A, et al. INHA, a gene encoding a target for isoniazid and ethionamide in Mycobacterium tuberculosis. Science 1994; 263(5144): 227-30.

[2] Floyd K, Blanc L, Raviglione M, Lee JW. Resources required for global tuberculosis control. Science 2002; 295 (5562): 2040-1.

[3] Garbe TR, Hibler NS, Deretic V. Isoniazid induces expression of the antigen 85 complex in Mycobacterium tuberculosis. Antimicrob Agents Chemother 1996; 40 (7): 1754-6.

[4] Gupta R, Kim JY, Espinal MA, et al. Public health: responding to market failures in tuberculosis control. Science 2001; 293(5532): 1049-51.

[5] Kuo MR, Morbidoni HR, Alland D, et al. Targeting tuberculosis and malaria through inhibition of enoyl reductase: compond activity and structural data. J Biol Chem 2003; 278(23): 20851-9.

[6] Zhang Y, Heym B, Allen B, Young D, Cole ST. The catalaseperoxidase gene and isoniazid resistance of Mycobacterium tuberculosis. Nature 1992; 358: 501-3.

[7] Lei B, Wei C-J, Tu S-C. Action mechanism of antitubercular isoniazide: activation by Mycobacterium tuberculosis KatG, isolation and characterization of inhA inhibitor. J Biol Chem 2000 ; 275 (4): 2520-6.

[8] Roohi S, Mushtaq A, Jehangir M, Malik SA. Direct labeling of isoniazid with technetium-99m for diagnosis of tuberculosis. Radiochim Acta 2006; 94 (3):147-52.

[9] Sameul G, Kothari K, Banerjee S, et al. On the ${ }^{99 \mathrm{~m}}$ Tc-labeling of isoniazid with different ${ }^{99 \mathrm{~m}} \mathrm{Tc}$ cores. J Label Compd Radiopharm 2005; 48 (5): 363-7.

[10] Sriram D, Yogeeswari P, Madhu K. Synthesis and in vitro and in vivo antimycobacterial activity of isonicotinoyl hydrazones. Bioorg Med Chem Lett 2005; 15 (20): 4502-5.

[11] Sinha N, Jain S, Tilekar A, et al. Synthesis of isonicotinic acid N'arylidene-N-[2-oxo-2-(4-aryl-piperazin-1-yl)-ethyl]-hydrazides as antituberculosis agents. Bioorg Med Chem Lett 2005; 15 (6): 15736.

[12] De Logu A, Onnis V, Saddi B, Congiu C, Schivo ML, Cocco MT. Activity of a new class of isonicotinoylhydrazones used alone and in combination with isoniazid, rifampicin, ethambutol, paraaminosalicylic acid and clofazimine against Mycobacterium tuberculosis. J Antimicrob Chemother 2002; 49 (2): 275-82.

[13] Vigorita MG, Ottanà R, Maccari R, Monforte F, Bisignano G, Pizzimenti FC. Synthesis and in vitro antimicrobial and antitumoral screening of novel lipophilic isoniazid analogues. VI. Boll Chim Farm 1998; 137 (7): 267-76. 
[14] Vigorita MG, Ottanà R, Zappalà $\mathrm{C}$, Maccari R, Pizzimenti FC, Gabbrielli G. Halogenated isoniazid derivatives as possible antimycobacterial and anti-HIV agents--III. Farmaco 1994; 49 (12):775-81.

[15] Seth V, Seth SD, Beotra A, Semwal OP, D'monty V, Mukhopadhya S. Isoniazid and acetylisoniazid kinetics in serum and urine in pulmonary primary complex with intermittent regimen. Indian Pediatr 1994; 31(3): 279-85.

[16] Hearn1 MJ, Cynamon MH. Design and synthesis of antituberculars: preparation and evaluation against Mycobacterium tuberculosis of an isoniazid Schiff base. J Antimicrob Chemother 2004; 53 (2):185-91.

[17] $\mathrm{Fu}$ Y, Laurent S, Muller RN. Synthesis of a sialyl lewis mimetic conjugated with DTPA, potential ligand of new contrast agents for medical imaging. Eur J Org Chem 2002; 2002 (23): 3966-73.

[18] Manual on isolation. Identification and sensitivity testing of Mycobacterium tuberculosis. Bangalore: National Tuberculosis Institute, 1998; pp. 24-9.
[19] Bryant RE, Mazza, JA. Effect of abscess environment of the antimicrobial activity of ciprofloxacin. Am J Med 1989; 87(Suppl): 23S-7S.

[20] Vinjamuri S, Hall AV, Solanki KK, et al. Comparison of $99 \mathrm{mTc}$ Infecton imaging with radiolabelled white cells imaging in the evaluation of bacterial infection. Lancet 1996; 347 (8996): 233-5.

[21] Welling MM, Lupetti A, Balter HS, Lanzzeri S, Souto B, Rey AM. Technetium-99m labelled antimicrobial peptides discriminate between bacterial infections and sterile inflammations. Eur J Nucl Med 2000; 27 (3): 292-01.

[22] Nibbering PH, Welling MM, van den Broek PJ, van Wyngaarden KE, Pauwels EKJ, Calame W. Radiolabelled antimicrobial peptides for imaging of infections. Nucl Med Commun 1998; 19 (12): 111721.

[23] Welling MM, Nibbering PH, Paulusma-Annema A, Hiemstra PS, Pauwels EKJ, Calame W. Imaging of bacterial infections with ${ }^{99 \mathrm{~m}}$ Tc-labeled human neutrophil peptide. J Nucl Med 1999; 40 (12): 2073-80.

Received: May 31, 2009

Revised: July 3, 2009

Accepted: October 21, 2009

(C) Hazari et al.; Licensee Bentham Open.

This is an open access article licensed under the terms of the Creative Commons Attribution Non-Commercial License (http: //creativecommons.org/licenses/by-nc/ 3.0/) which permits unrestricted, non-commercial use, distribution and reproduction in any medium, provided the work is properly cited. 